MATEC Web of Conferences 19, 01038 (2014)

DOI: $10.1051 /$ matecconf/ 20141901038

(C) Owned by the authors, published by EDP Sciences, 2014

\title{
Droplet evaporation in water jet at the motion through high temperature gases
}

\author{
Pavel A. Strizhak ${ }^{1}$, Roman S. Volkov ${ }^{1, a}$, Elena Yu. Kurilenko ${ }^{2}$ \\ ${ }^{1}$ National Research Tomsk Polytechnic University, 634050 Tomsk, Russia \\ ${ }^{2}$ Tyumen State University of Architecture and Civil Engineering, 625001 Tyumen, Russia
}

\begin{abstract}
Heat and mass transfer model for the numerical investigation of the evaporation process of a single droplet in water jet when moving through high temperature gases was developed. The integral characteristics of the process under investigation were calculated. The macroscopic regularities of water droplet evaporation, as elements of jet, in the high temperature gas mixture (as exemplified by combustion products of typical condensed substances) were determined.
\end{abstract}

\section{Introduction}

Numerical [1-3] and experimental [4-6] investigations of evaporation completeness and utilization efficiency of atomized water showed that the large volume usage of extinguishing composition when neutralizing of large-scale fires (including forest fires) is insufficiently substantiated more often than not. The full-scale experiment carrying out concerning the extinguishing of open fire seats is sufficiently difficult even for relatively simple conditions in closed spaces. Such analysis is still more difficult in case of forest fires. The usage of numerical simulation for investigation of heat and mass transfer processes under the interoperating of atomized water with high temperature combustion products is appropriate taking into account the necessity concerning the providing of safety conditions and the minimization of material expenses.

The purpose of the article is a numerical simulation of heat and mass transfer processes when moving the single droplets, as elements of jet, through high temperature combustion products of the typical combustible condensed substance.

\section{Problem statement and solution methods}

The problem with principle diagram shown in Figure 1 was solved to determine the motion speed of water droplet in jet flowing into high temperature gas mixture. It was thought that the boundary-layer approximation can use during the numerical analysis of jet flow.

Nowadays, the different systems of extinguishing composition introducing in high temperature combustion products are known. Inflators and atomizers being applied for fire extinguishing are widely used. Therefore, the water jet may have different configurations and motion trajectories after spraying. There is a good reason to consider in a first approximation a sufficiently typical and simplest

${ }^{\text {a }}$ Corresponding author: romanvolkov@tpu.ru

This is an Open Access article distributed under the terms of the Creative Commons Attribution License 4.0, which permits unrestricted use, distribution, and reproduction in any medium, provided the original work is properly cited. 
jet configuration (Figure 1) forming during the water jettison (for instance, from the aircraft) without atomization (in the form of "water column").

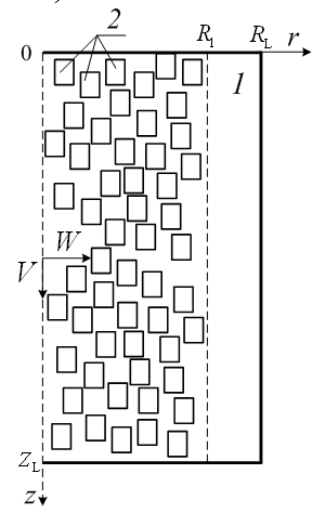

Figure 1. A schematic illustration of solution region for water jet flow problem with boundary-layer approximation: 1 - high temperature combustion products, 2 - water droplets.

The analysis of "water column" motion conditions with sufficiently large dimensions (in comparison with single droplet dimensions) shows that the water supply in a first approximation during the simulation can be considered as a constant. Therefore, the unsteady-state conditions cannot be considered in determining the longitudinal and transverse velocity fields in the jet (Figure 1) and used the typical system of stationary differential equations for the boundary layer:

$0<r<R_{1}, 0<z<Z_{\mathrm{L}}$

$$
\begin{gathered}
V \frac{\partial V}{\partial z}+W \frac{\partial V}{\partial r}=\frac{v}{r} \frac{\partial}{\partial r}\left[r \frac{\partial V}{\partial r}\right], \\
\frac{\partial V}{\partial z}+\frac{\partial W}{\partial r}+\frac{W}{r}=0,
\end{gathered}
$$

where $r, z$ - coordinates of cylindrical system, $\mathrm{m} ; V$ - jet velocity in the direction of motion (along $z$ axis), $\mathrm{m} / \mathrm{s} ; W-$ jet velocity in the orthogonal direction to the motion vector (along $r$-axis), $\mathrm{m} / \mathrm{s} ; v-$ kinematic viscosity, $\mathrm{m}^{2} / \mathrm{s}$.

Boundary conditions (Figure 1):

$$
W=0, \frac{\partial V}{\partial r}=0 \text { at } r=R_{1} ; W=W_{0}, V=V_{0} \text { at } r=0,
$$

where $V_{0}, W_{0}$ - initial velocity profiles, $\mathrm{m} / \mathrm{s}$.

Longitudinal jet velocity $V$ on the axis of symmetry (Figure 1) was determined using the droplet motion equation in this section:

$$
\frac{d V_{\mathrm{d}}}{d t}=\frac{3 \rho_{3}}{4 \rho_{2} R_{\mathrm{d}}} c_{\chi}\left|V_{\mathrm{d}}-V_{\mathrm{e}}\right|\left(V_{\mathrm{d}}-V_{\mathrm{e}}\right)+g
$$

where $V_{\mathrm{d}}$ - droplet motion speed on the symmetry axis of the jet, $\mathrm{m} / \mathrm{s} ; \rho_{2}, \rho_{3}$ - density of water and water vapor, $\mathrm{kg} / \mathrm{m}^{3} ; R_{\mathrm{d}}$ - droplet characteristic dimension in the orthogonal direction to the motion vector of the droplet, $\mathrm{m} ; c_{\chi}$ - nondimensional coefficient of resistance to motion; $V_{\mathrm{e}}$ - linear velocity of water vapor outflow from the droplet side surfaces, $\mathrm{m} / \mathrm{s} ; g-$ gravity factor, $\mathrm{m} / \mathrm{s}^{2}$.

Velocity distributions $V$ and $W$ were obtained in consequence of a computational solution of the simultaneous equations (1)-(4). Longitudinal velocity $V$ distribution in water jet at $V_{0}=0.5 \mathrm{~m} / \mathrm{s}$, $W_{0}=0.05 \mathrm{~m} / \mathrm{s}, R_{1}=3 \mathrm{~mm}$ is shown in Figure 2 . The most typical motion conditions of jet in the high temperature gas mixture in the form of "water column" were simulated.

Let's consider the full flashing conditions of droplet moving into the outer contour of jet $\left(r=R_{1}\right)$ and at a definite distance in the direction of the symmetry axis from its side "edge".

A schematic illustration of solution region of heat and mass transfer problem for droplet is shown in Figure 3. The axisymmetric statement is used similarly to [1-3]. 


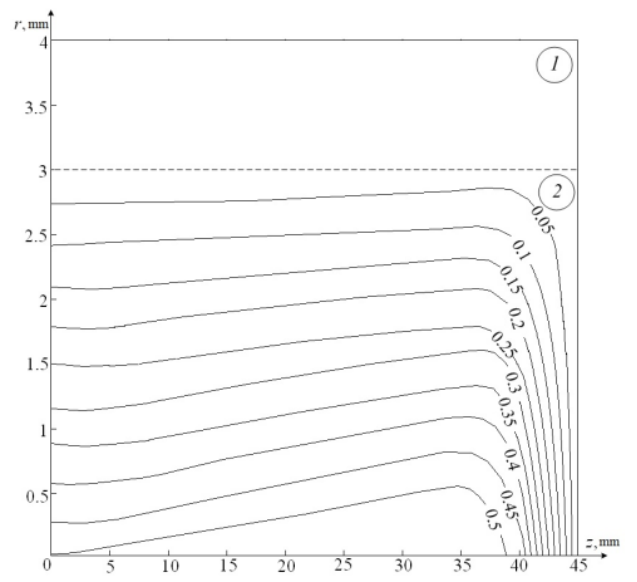

Figure 2. A longitudinal velocity $(V, \mathrm{~m} / \mathrm{s})$ distribution in a water jet at $V_{0}=0.5 \mathrm{~m} / \mathrm{s}, W_{0}=0.05 \mathrm{~m} / \mathrm{s}, R_{1}=3 \mathrm{~mm}: 1$ - high temperature combustion products, 2 - water droplets.

The initial temperature $T_{0}$ of droplet was significantly lower than the gas mixture temperature $T_{\mathrm{f}}$ equal to the average temperature of fire.

The droplet motion speed was calculated using the boundary-layer approximation (Figure 1) during the solution of the problem described above. At the same time, the effect of motion resistance forces and the gravity action was taken into consideration.

It was thought that the droplet is heated by thermal conductivity while analyzing the droplet evaporation conditions in the system under consideration (Figure 3). The evaporation takes place achieving the phase transformation conditions on the "liquid - high temperature gas mixture" boundary. The water vapors are blown into the gas area and mixed with combustion products. The gas mixture temperature in close proximity to the droplet motion trajectory is decreased by the heat energy of endothermic phase transformation and the blowing of vapors. The droplet dimensions are decreased under the conditions of intensive vapor formation. The droplet full flashing takes place under certain conditions.

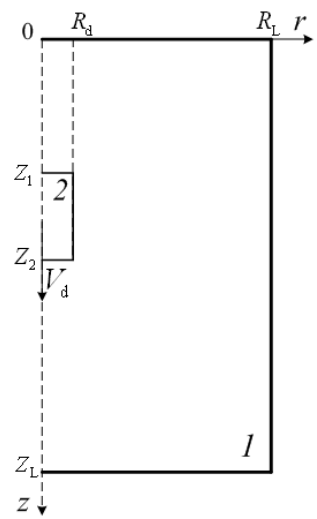

Figure 3. A schematic illustration of solution region for heat and mass transfer problem in coordination of a single droplet with the high temperature combustion products.

The following assumptions were made during the numerical simulation of droplet motion in the high temperature combustion product area (Figure 3):

1. The droplet has cylinder form elongated toward moving (Figure 3). The droplet configuration is not changed when moving. The droplets, as a rule, are merged and then they form the complicated configurations ("drop-shaped"). The numerical simulation of heat and mass transfer processes under the conditions of phase transformations in the area with inner boundary of such configuration is quite difficult to carry out. Currently, the numerical solution results of such problems were not published. 


\section{MATEC Web of Conferences}

2. The gas area represents a "fire gases-water vapor" system. The blend composition of combustion products is not detailed when simulating, since it is slightly changed for the large group of combustible substances and materials [1-3].

3. The frictional forces on a surface of stream-lined body (droplet) (Figure 3) are not taken into account, since, it can be neglected the effect of these forces under low speeds and the droplet dimensions.

4. The thermal and physical characteristics of combustion products, water and water vapor do not depend on the temperature. The analysis results [1-3] show that this factor in a first approximation can be neglected for temperature range under consideration.

The methods and the problem algorithm of jet flow using the boundary-layer approximation and the solution methods of nonstationary differential equation system for a single droplet are similar to the methods and the algorithm described in [1-3].

The evaluation methods of the carried out investigation results validity based on the conservatism checking of an applying difference scheme are similar to the methods used in [7-11].

\section{Results and discussion}

Numerical investigations were carried out using the following most typical parameter values [12, 13] initial water droplet temperature $T_{0}=300 \mathrm{~K}$; combustion product temperature $T_{\mathrm{f}}=1170 \mathrm{~K}$; thermal effect of water evaporation $Q_{\mathrm{e}}=2.26 \mathrm{MJ} / \mathrm{kg}$; droplet dimensions $R_{\mathrm{d}}=0.25 \div 0.5 \mathrm{~mm}, L_{\mathrm{d}}=0.5 \div 1 \mathrm{~mm}$; characteristic jet dimension $R_{1}=3 \div 10 \mathrm{~mm}$; solution region dimensions $Z_{\mathrm{L}}=1 \mathrm{~m}, R_{\mathrm{L}}=0.01 \mathrm{~m}$; initial jet motion velocities $V_{0}=0.5 \mathrm{~m} / \mathrm{s}, W_{0}=0.05 \mathrm{~m} / \mathrm{s}$; water molecular mass $M=18 \mathrm{~kg} / \mathrm{kmol}$. Thermal and physical characteristics of water, water vapor and combustion products of typical condensed substance (kerosene) were selected in accordance with $[12,13]$.

Figure 2 shows that the droplet motion velocity on the jet external boundary $\left(r \rightarrow R_{1}\right)$ does not exceed $0.05 \mathrm{~m} / \mathrm{s}$ (under the typical parameters of "water column" $V_{0}=0.5 \mathrm{~m} / \mathrm{s}, W_{0}=0.05 \mathrm{~m} / \mathrm{s}$, $R_{1}=3 \mathrm{~mm}$ ). The evaporation conditions and water droplets moving to the jet external boundary (Figure 1) with such low speed are appropriate to analyze. It was established that the full flashing time td does not exceed $0.6 \mathrm{~s}$ at the droplet motion in this jet section under the conditions of high temperature combustion products $\left(T \rightarrow T_{\mathrm{f}}\right)$. The droplet path in the combustion product area is extremely short (less than $0.1 \mathrm{~m}$ ), when the droplet motion velocity is less than $0.05 \mathrm{~m} / \mathrm{s}$. Inference should be drawn that the droplets in this jet section are evaporated practically immediately without the creation of any important "vapor trajectories (tracks)". However, the evaporation processes in the jet external boundary $(r \rightarrow R 1)$ influence significantly on the evaporation history of neighboring and subsequent layers of "water column".

It has already been established that two "neighboring" droplets in the flow can influence significantly on the evaporation conditions of each other. Two droplets can be considered as a "monolithic" droplet, when the droplet spacing is less than a half of its characteristic dimension. The obtained isotherms and the isolines of water vapor concentrations under the droplet spacing comparable to $R_{\mathrm{d}}$ are shown in Figure 4 . It can be seen that the combustion product temperature (Figure 4,a) is significantly decreased in the area between droplets. Consequently, the evaporation process is slow and the mass of blowing water vapors is decreased (Figure $4, b$ ). These results carry inference that the evaporation times of each subsequent droplet (when moving the jet to the axis of symmetry) exceed by several times the droplet evaporation times on the internal boundary $\left(r \rightarrow R_{1}\right)$.

Thus, for example, the numerical analysis of droplet evaporation conditions moving inside the jet under the removal from the external boundary to the axis of symmetry on $2 \div 3$ characteristic dimensions $\left(2 \div 3 R_{\mathrm{d}}\right)$ shows that the times td for a droplet removed on $2 \div 3 R_{\mathrm{d}}$ grow up to $0.9 \div 1.2 \mathrm{~s}$ by means of significant temperature decreasing in reference to $T_{\mathrm{f}}$ (in consequence of ingress of phase transformation heat on the external boundary). In addition to the above, the path in the high temperature combustion product area is significantly increased (a path is increased by $4 \div 5$ times in relation to droplets moving to the external boundary of the boundary layer at the average droplet velocity $0.3 \mathrm{~m} / \mathrm{s}$ ). 
The $2^{\text {nd }}$ International Youth Forum "Smart Grids"
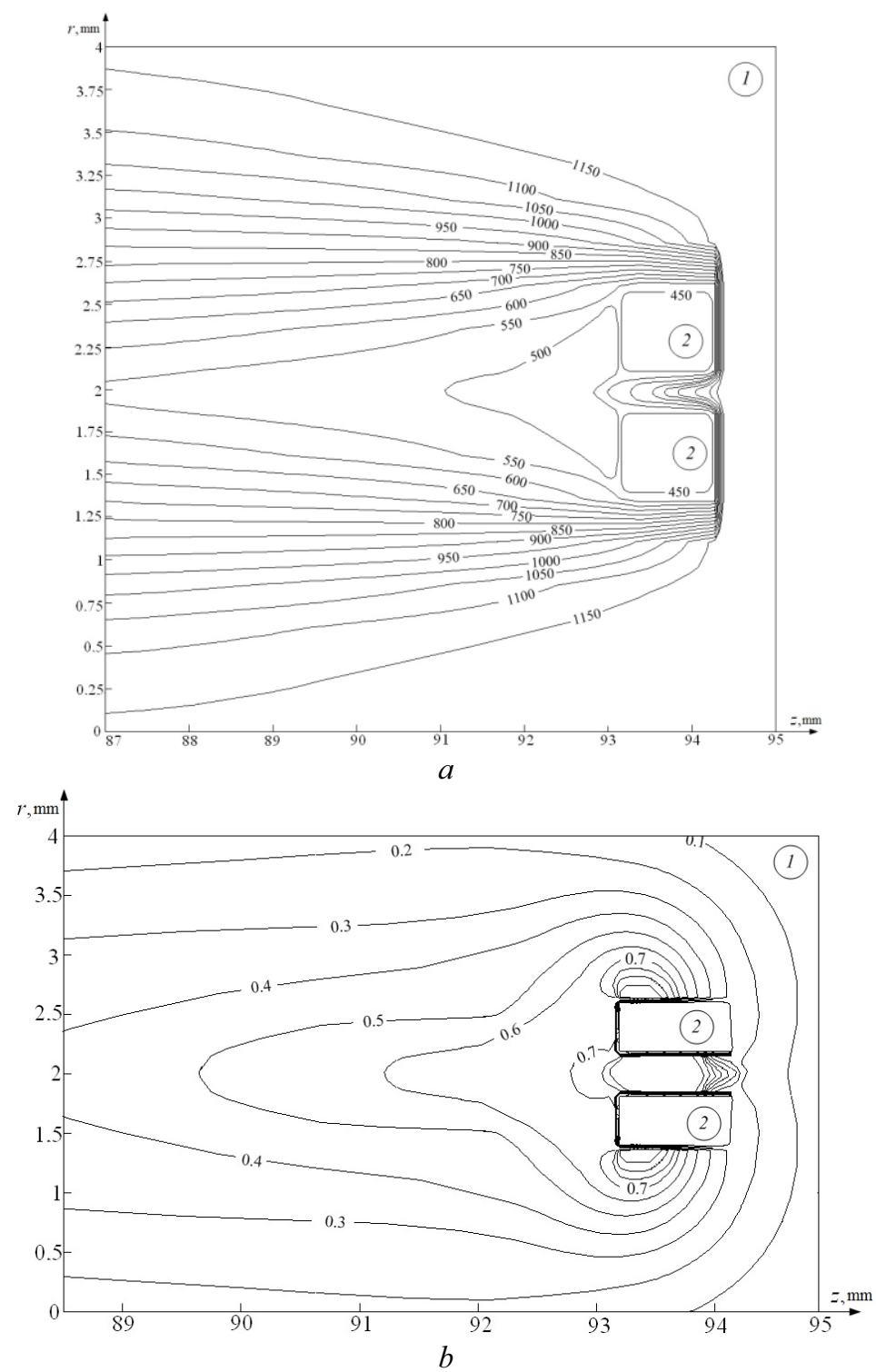

Figure 4. Isotherms $(T, \mathrm{~K})$ and concentration isolines of water vapors $\left(C_{\mathrm{w}}\right)$ in the system with two droplets at $t=$ $0.1 \mathrm{~s}, T_{\mathrm{f}}=1170 \mathrm{~K}, R_{\mathrm{d}}=0.25 \mathrm{~mm}, L_{\mathrm{d}}=1 \mathrm{~mm}, L_{\mathrm{n}}=0.3 \mathrm{~mm}: 1$ - high temperature combustion products, $2-$ water droplets.

It was established that the full flashing time of a single droplet moving to the high temperature combustion products area with a velocity determined from equation (3) at $R_{\mathrm{d}}=0.25 \mathrm{~mm}, L_{\mathrm{d}}=1 \mathrm{~mm}$, $V_{0}=0.5 \mathrm{~m} / \mathrm{s}$ equals to $0.46 \mathrm{~s}$. Moreover, the droplet path is slightly less than $0.7 \mathrm{~m}$. The time $t_{\mathrm{d}}$ is slightly more $\left(t_{\mathrm{d}}=0.58 \mathrm{~s}\right)$ than for a "separate" single droplet when considering the droplet, as the jet element, in the external boundary $\left(r \rightarrow R_{1}\right)$. However, the droplet path, as the jet element, does not exceed $0.1 \mathrm{~m}$ due to the low speed (approximately $0.05 \mathrm{~m} / \mathrm{s}$ ). Obtained result can be explained by reason that the heat exchange capacity and the water vapor outflow velocity are increased rising the droplet motion velocity. The droplet dimensions are decreased faster. But at that time the path grows. If the droplets in the sections approaching to the jet axis of symmetry, then it is possible to say both about the increasing of droplet evaporation time $t_{\mathrm{d}}$ and the path. 
Taking into account the obtained results, inference should be drawn that the path exceeds $2 \div 3$ meters (at the average temperature of fire $T=T_{\mathrm{f}}$ ) under the condition of jet characteristic diameter up to $10 \mathrm{~mm}$ ("water columns" dimensions significantly exceed $10 \mathrm{~mm}$ when extinguishing the forest fires) under the considered conditions for more than a half of water weight. This result once more suggests that the dropping of large water mass ("water slug") without special atomization is not effective. The optimal droplet crushing and the atomization in across-track direction with respect to the motion vector of "water slug".

Analyzing the dependencies of droplet evaporation times on its dimensions and gas mixture temperature, which were shown above and obtained on the results of this article, inference should be drawn that the evaporation conditions of "separate" single droplets are different from the evaporation conditions in the water jet. The droplet velocity and the "cooperative" effect of droplets moving to the neighboring jet layers on the intensity of heat and mass transfer are the most important.

\section{Conclusions}

Obtained results show that the droplet full flashing times nearby the jet internal boundary is short. At the same time, these times slightly exceed the evaporation times of "separate" single water droplets moving due to gravity and resistant force. Determined characteristic property is conditional upon the significant impact of droplet motion velocity on the evaporating rate (the higher motion speed, the less the droplet existence time). Also, it was shown that the times td are significantly increased for the droplets moving to neighboring jet layers in relation to its internal boundary in spite of motion speed increase. It is explained by the temperature decreasing in the neighborhood of "internal" droplets under an intensive evaporation of external boundary.

The consideration of heat and mass transfer processes when moving the single droplet inside the high temperature gas mixture as a part of droplet complex moving with a velocity of water jet allowed essentially clarifying the concepts about a mutual effect conditions of "water slugs" with combustion products of typical fuels.

The investigation was performed by Russian Science Foundation grant (project 14-39-00003).

\section{References}

1. O.V. Vysokomornaya, G.V. Kuznetsov, P.A. Strizhak, J. Eng. Phys. and Thermophys. 1, 86 (2013)

2. P.A. Strizhak, J. Eng. Phys. and Thermophys. 4, 86 (2013)

3. D.O. Glushkov, G.V. Kuznetsov, P.A. Strizhak, Math. Probl. in Eng. 2014 (2014)

4. R.S. Volkov, G.V. Kuznetsov, P.A. Strizhak, Tech. Phys. 7, 59 (2014)

5. R.S. Volkov, O.V. Vysokomornaya, G.V. Kuznetsov, P.A. Strizhak, J. Eng. Phys. and Thermophys. 6, 86 (2013)

6. R.S. Volkov, O.V. Vysokomornaya, G.V. Kuznetsov, P.A. Strizhak, Adv. in Mech. Eng. 2014, (2014)

7. D.O. Glushkov, G.V. Kuznetsov, P.A. Strizhak, Adv. in Mech. Eng. 2014 (2014)

8. O.V. Vysokomornaya, G.V. Kuznetsov, P.A. Strizhak, Math. Probl. in Eng. 2014 (2014)

9. O.V. Vysokomornaya, G.V. Kuznetsov, P.A. Strizhak, Russ. J. Phys. Chem. B 4 (2011)

10. D.O. Glushkov, G.V. Kuznetsov, P.A. Strizhak, Russ. J. Phys. Chem. B 3, 7 (2013)

11. O.V. Vysokomornaya, G.V. Kuznetsov, P.A. Strizhak, Math. Probl. in Eng. 2014 (2014)

12. N.B. Vargaftik, L.P. Filipov, A.A. Tarzimanov, E.E. Totskii, Handbook of Thermal Conductivity of Liquids and Gases (CRC Press, Inc., Boca Raton, 1994)

13. J.O. Hirschfelder, C.F. Curtiss R.B. Bird, Molecular Theory of Gases and Liquids (John Wiley and Sons, New York, 1954) 